\title{
PENENTUAN RAINBOW CONNECTION NUMBER DAN STRONG RAINBOW CONNECTION NUMBER PADA GRAF BERLIAN
}

\author{
SUCI RIEZSA DESSYLUVIANI \\ Program Studi Matematika, \\ Fakultas Matematika dan Ilmu Pengetahuan Alam, Universitas Andalas, \\ Kampus UNAND Limau Manis Padang, Indonesia, \\ email : suciriezsadessyluviani@yahoo.co.id
}

\begin{abstract}
Abstrak. Misalkan $G=(V, E)$ adalah suatu graf. Suatu pewarnaan $c: E(G) \rightarrow$ $\{1,2, \cdots, k\}, k \in \mathbb{N}$ pada graf $G$ adalah suatu pewarnaan sisi di $G$ sedemikian sehingga setiap sisi bertetangga boleh berwarna sama. Misalkan $u, v \in V(G)$ dan $P$ adalah suatu lintasan dari $u$ ke $v$. Suatu intasan $P$ dikatakan rainbow path jika tidak terdapat dua sisi di $P$ berwarna sama. Graf $G$ disebut rainbow connected dengan pewarnaan $c$ jika untuk setiap $u, v \in V(G)$ terdapat rainbow path dari $u$ ke $v$. Jika terdapat $k$ warna di $G$ maka $c$ adalah rainbow k-coloring. Rainbow connection number dari graf terhubung dinotasikan dengan $r c(G)$, didefinisikan sebagai banyaknya warna minimal yang diperlukan untuk membuat graf $G$ bersifat rainbow connected. Selanjutnya, pewarnaan $c$ dikatakan pewarnaan- $k$ strong rainbow, jika untuk setiap titik $u$ dan $v$ di $V$ terdapat lintasan pelangi dengan panjangnya sama dengan jarak $u$ dan $v$. Dalam makalah ini akan ditentukan rainbow connection number dan Strong Rainbow Connection Number pada graf Berlian dengan $2 n$ titik. Graf Berlian, dinotasikan dengan $B r_{n}$, adalah graf yang diperoleh dari graf tangga segitiga dengan $2 n-1$ titik, dengan menambahkan satu titik dan beberapa sisi tertentu. Dalam makalah ini akan ditentukan $r c\left(B r_{n}\right)$ dan $\operatorname{src}\left(B r_{n}\right)$ untuk $n \geq 4$.
\end{abstract}

Kata Kunci: Rainbow connection number, Strong rainbow connection number, Graf Berlian, Lintasan, Pewarnaan Rainbow

\section{Pendahuluan}

Konsep rainbow connection number pada graf pertama kali diperkenalkan oleh Chartrand, dkk pada tahun 2005. Misalkan $G=(V, E)$ adalah suatu graf terhubung tak trivial. Pewarnaan $c: E(G) \rightarrow\{1,2, \cdots, k\}, k \in \mathbb{N}$ adalah suatu pewarnaan, sedemikian sehingga dua sisi yang bertetangga boleh memiliki warna yang sama. Suatu $u-v$ path $P$ di $G$ dikatakan rainbow path jika tidak ada dua sisi di $P$ yang memiliki warna sama. Graf $G$ dikatakan rainbow connected jika setiap dua titik yang berbeda di $G$ dihubungkan oleh rainbow path. Dalam hal ini, pewarnaan graf $G$ disebut rainbow coloring. Jika ada sebanyak $k$ warna yang digunakan, maka pewarnaannya disebut rainbow $k$-coloring. Bilangan $k$ disebut bilangan rainbow connection (rainbow connection number) dari graf terhubung $G$, dilambangkan dengan $r c(G)$, didefinisikan sebagai banyaknya minimum warna yang diperlukan untuk mewarnai sisi graf $G$ sehingga graf tersebut bersifat rainbow connected.

Misalkan $c$ adalah rainbow coloring dari graf terhubung $G$. Untuk setiap dua titik 
$u$ dan $v$ di $G$, suatu rainbow $u$-v geodesic di $G$ adalah lintasan rainbow $u$ - $v$ dengan panjang $d_{G}(u, v)$, yaitu jarak antara $u$ dan $v$ di $G$. Graf $G$ disebut strongly rainbow connected jika memuat suatu rainbow $u$ - $v$ geodesic untuk setiap dua titik $u, v$ di $G$. Dalam hal ini pewarnaan $c$ dinamakan strong rainbow coloring di $G$. Bilangan strong rainbow connection (strong rainbow connection number) dari graf terhubung $G$, dilambangkan dengan $\operatorname{src}(G)$, didefinisikan sebagai minimum dari banyaknya warna yang diperlukan untuk memuat $G$ menjadi strong rainbow connected [1].

Dalam makalah ini akan dibahas tentang penentuan rainbow connection number dan strong rainbow connection number pada graf berlian, dimana graf berlian adalah graf yang berasal dari graf tangga segitiga yang titik ujungnya dihilangkan atau dihapus.

\section{Kajian Pustaka}

Hubungan $\operatorname{diam}(G), r c(G), \operatorname{src}(G)$ dan banyak sisi $m$ pada suatu graf terhubung $G$ akan dijelaskan pada proposisi berikut.

Proposisi 2.1. [2] Misalkan $G$ adalah graf terhubung tak trivial berukuran $m$. Jika $c: E(G) \rightarrow\{1,2, \cdots, k\}, k \in \mathbb{N}$ merupakan rainbow coloring, maka

$$
\operatorname{diam}(G) \leq r c(G) \leq \operatorname{src}(G) \leq m .
$$

\section{Penentuan Rainbow Connection Number pada Graf Berlian}

Teorema 3.1. [4] Misalkan bilangan bulat $n \geq 4$, maka rainbow connection number untuk graf berlian berorde $2 n$ adalah $r c\left(B r_{n}\right)=\operatorname{diam}\left(B r_{n}\right)$.

Bukti. Berdasarkan pertidaksamaan (2.1), cukup diperlihatkan $\operatorname{rc}\left(B r_{n}\right) \leq$ $\operatorname{diam}\left(B r_{n}\right)$. Untuk itu pembuktian akan dibagi ke dalam dua kasus.

Kasus 1. Untuk $n=4$ atau $n=5$, definisikan pewarnaan $c: E(G) \rightarrow\{1,2,3\}$ sebagai berikut :

$$
\begin{aligned}
c\left(u_{i} u_{i+1}\right) & =i, \text { untuk } i \in\{1,2,3,4\}, \\
c\left(u_{i} v_{i}\right) & =c\left(u_{i} v_{i+1}\right)=3, \text { untuk } i \in\{1,2,3,4\}, \\
c\left(v_{i} v_{i+1}\right) & =((i+1) \bmod 2)+1, \text { untuk } i \in\{1,2,3,4\}, \\
c\left(v_{i} v\right) & =\left\lfloor\frac{i}{4}\right\rfloor+1, \text { untuk } i \in\{1,2,3,4\} .
\end{aligned}
$$

Selanjutnya, akan ditunjukkan bahwa untuk setiap $x$ dan $y$ di $V\left(B r_{n}\right)$ dengan $d(x, y) \geq 2$ terdapat path $x-y$ yang merupakan rainbow path.

Sub-kasus 1.1 Jika $x=v$ dan $y=u_{i}$, maka terdapat rainbow path $v, v_{i}, u_{i}$. Contoh : $v, v_{1}, u_{1}$.

Sub-kasus 1.2 Misalkan $x=u_{i}$ dan $y=u_{j}$ dengan $i<j$

Jika $d(x, y)=2$, maka terdapat rainbow path $u_{i}, u_{i+1}, u_{j}$.

Contoh : $u_{1}, u_{2}, u_{3}$.

Jika $d(x, y)=3$, maka terdapat rainbow path $u_{i}, u_{i+1}, u_{i+2}, u_{j}$.

Contoh : $u_{1}, u_{2}, u_{3}, u_{4}$ 
Sub-kasus 1.3 Misalkan $x=v_{i}$ dan $y=v_{j}$ dengan $i<j$.

Jika $j-i \geq 3$ maka terdapat rainbow path $v_{i}, v, v_{j}$.

Contoh : $v_{1}, v, v_{4}$.

Jika $j-i=2$ maka terdapat rainbow path $v_{i}, v_{i+1}, v_{j}$.

Contoh : $v_{1}, v_{2}, v_{3}$.

Sub-kasus 1.4 Misalkan $x=v_{i}$ dan $y=u_{j}$.

Jika $|j-i|=1$ maka terdapat rainbow path $v_{i}, u_{i}, u_{j}$.

Contoh : $v_{1}, u_{1}, u_{2}$ atau $v_{2}, u_{2}, u_{1}$

Jika $i-j>1$, maka terdapat rainbow path $v_{i}, v, v_{j+1}, u_{j}$.

Contoh : $v_{3}, v, v_{2}, u_{2}$.

Jika $j-i>1$, maka terdapat rainbow path $v_{i}, v, v_{j}, u_{j}$.

Contoh : $v_{1}, v, v_{3}, u_{3}$.

Karena itu, path $c$ adalah suatu lintasan rainbow pada $B r_{4}$ dan $B r_{5}$. Akibatnya, $r c\left(B r_{n}\right)$ untuk $n=4$ atau $n=5$.

Kasus 2. $n \geq 6$.

Definisikan pewarnaan $c: E(G) \rightarrow\{1,2,3,4\}$ sebagai berikut :

$$
\begin{aligned}
c\left(u_{i} u_{i+1}\right) & =1, \text { untuk } i \in\{1,2, \cdots, 8\}, \\
c\left(v_{i} v_{i+1}\right) & =c\left(u_{i} v_{i+1}\right)=i \bmod 2+3, \text { untuk } i \in\{1,2, \cdots, 8\}, \\
c\left(u_{i} v_{i}\right) & =((i+1) \bmod 2)+3, \text { untuk } i \in\{1,2, \cdots, 8\}, \\
c\left(v v_{j}\right) & =((j+1) \bmod 2)+1, \text { untuk } j \in\{1,2, \cdots, 8\} .
\end{aligned}
$$

Selanjutnya, akan ditunjukkan bahwa untuk setiap $x$ dan $y$ di $V\left(B r_{n}\right)$ dengan $d(x, y) \geq 2$, terdapat path $x-y$ yang merupakan rainbow path.

Sub-kasus 2.1 Jika $x=v$ dan $y=u_{i}$, maka terdapat rainbow path $v, v_{i}, u_{i}$. Contoh : $v, v_{1}, u_{1}$.

Sub-kasus 2.2 Misalkan $x=u_{i}, y=u_{j}$ dengan $i<j$.

Jika $i$ dan $j$ memiliki varitas yang sama, maka terdapat rainbow path $u_{i}, v_{i}, v, v_{j+1}, u_{j}$. Jika $i$ dan $j$ memiliki varitas yang berbeda, maka terdapat rainbow path $u_{i}, v_{i}, v, v_{j}, u_{j}$.

Sub-kasus 2.3 Misalkan $x=v_{i}, y=v_{j}$ dengan $i<j$.

Jika $i$ dan $j$ memiliki varitas yang sama, maka terdapat rainbow path $v_{i}, v, v_{j-1}, v_{j}$. Jika $i$ dan $j$ memiliki varitas yang berbeda, maka terdapat rainbow path $v_{i}, v, v_{j}$.

Sub-kasus 2.4 Misalkan $x=v_{i}$ dan $y=u_{j}$.

Jika $i$ dan $j$ memiliki varitas yang sama, maka terdapat rainbow path $v_{i}, v, v_{j+1}, u_{j}$. Jika $i$ dan $j$ memiliki varitas yang berbeda, maka terdapat rainbow path $v_{i}, v, v_{j}, u_{j}$.

Dari pertidaksamaan (2.1) dan definisi pewarnaan di atas, diperoleh $r c\left(B r_{n}\right)=4$ untuk $n \geq 6$.

Sebagai contoh, pada Gambar 1 diberikan suatu pewarnaan-3 pada graf $B r_{5}$. Sementara pada Gambar 2 dibuat suatu pewarnaan-4 rainbow pada $B r_{9}$. 


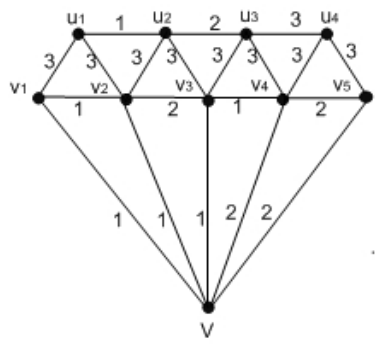

Gambar 1. Pewarnaan-3 pada rainbow $\mathrm{Br}_{5}$

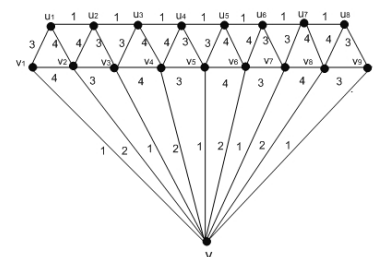

Gambar 2. Pewarnaan-4 pada $B r_{9}$

\section{Penentuan Strong Rainbow Connection Number pada Graf} Berlian

Teorema 4.1. [4] Misalkan bilangan bulat $n \geq 4$, maka strong rainbow connection pada graf berlian berorde $2 n$ adalah

$$
\operatorname{src}\left(B r_{n}\right)= \begin{cases}3, & \text { untuk } n=4 \text { atau } n=5 \\ \left\lceil\frac{n}{3}\right\rceil+2, & \text { untuk } n \geq 6 .\end{cases}
$$

Bukti. Kasus 1. Untuk $n=4$ atau $n=5$, definisikan pewarnaan $c: E(G) \rightarrow$ $\{1,2,3\}$ sebagai berikut :

$$
\begin{aligned}
c\left(u_{i} u_{i+1}\right) & =i, \text { untuk } i \in\{1,2,3,4\}, \\
c\left(u_{i} v_{i}\right) & =c\left(u_{i} v_{i+1}\right)=3, \text { untuk } i \in\{1,2,3,4\}, \\
c\left(v_{i} v_{i+1}\right) & =((i+1) \bmod 2)+1, \text { untuk } i \in\{1,2,3,4\}, \\
c\left(v_{i} v\right) & =\left\lfloor\frac{i}{4}\right\rfloor+1, \text { untuk } i \in\{1,2,3,4,5\} .
\end{aligned}
$$

Berdasarkan definisi pewarnaan di atas diperoleh $c: E\left(B r_{n}\right) \rightarrow\{1,2,3\}$, untuk $n=4$ dan $n=5$. Dengan demikian $r c\left(B r_{n}\right) \leq 3$ untuk $n=4$ dan $n=5$. Dari Teorema 3.1 Kasus 1 didapatkan $r c\left(B r_{n}\right)=3$ untuk $n=4$ dan $n=5$, karena $r c\left(B r_{n}\right)=3$ untuk $n=4$ dan $n=5$ berdasarkan pertidaksamaan 2.1 maka diperoleh $\operatorname{src}\left(B r_{n}\right) \geq 3$ untuk $n=4$ dan $n=5$. Dengan demikian dapat dibuktikan $\operatorname{src}\left(B r_{n}\right)=3$ untuk $n=4$ dan $n=5$.

Kasus 2. Untuk $n \geq 6$. Misalkan $t=\left\lceil\frac{n}{3}\right\rceil+2$ untuk $n=6$, karena $r c\left(B r_{n}\right)=4$. Berdasarkan pertidaksamaan 2.1 maka $\operatorname{src}\left(B r_{6}\right) \geq 4$ untuk $n=6$ maka $t=4$. Akan 
ditunjukkan $\operatorname{src}\left(B r_{6}\right) \leq 4$. Diberikan definisi pewarnaan graf $B r_{6}$ sebagai berikut.

Pewarnaan $c: E(G) \rightarrow\{1,2,3,4\}$ sebagai berikut :

$$
\begin{aligned}
c\left(u_{i} u_{i+1}\right) & =1, \text { untuk } i \in\{1,2, \cdots, 5\}, \\
c\left(v_{i} v_{i+1}\right) & =c\left(u_{i} v_{i+1}\right)=i \bmod 2+3, \text { untuk } i \in\{1,2, \cdots, 5\}, \\
c\left(u_{i} v_{i}\right) & =((i+1) \bmod 2)+3, \text { untuk } i \in\{1,2, \cdots, 5\}, \\
c\left(v v_{j}\right) & =((j+1) \bmod 2)+1, \text { untuk } j \in\{1,2, \cdots, 6\} .
\end{aligned}
$$

Berdasarkan definisi pewarnaan graf $B r_{6}$ maka diperoleh $\operatorname{src}\left(B r_{6}\right) \leq 4$. Dengan demikian dapat dibuktikan $\operatorname{src}\left(B r_{6}\right)=4$.

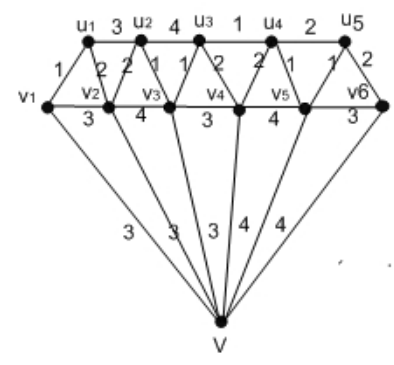

Gambar 3. Graf $\mathrm{Br}_{6}$

Selanjutnya, akan dibuktikan bahwa $\operatorname{src}\left(B r_{6}\right) \geq t$ untuk $n \geq 7$ dengan $t=$ $\left\lceil\frac{n}{3}\right\rceil+2$ karena $r c\left(B r_{n}\right)=4$ untuk $n \geq 7$ maka berdasarkan pertidaksamaan 2.1, $\operatorname{src}\left(B r_{n}\right) \geq 4$ untuk $n \geq 7$. Misal untuk $n=7$ maka $t=5$.

Akan ditunjukkan $\operatorname{src}\left(B r_{7}\right) \neq t-1$ sehingga $\operatorname{src}\left(B r_{7}\right)=t$. Warnai graf $B r_{7}$ dengan pewarnaan graf $B r_{6}$ dapat diilustrasikan seperti pada Gambar 3.4

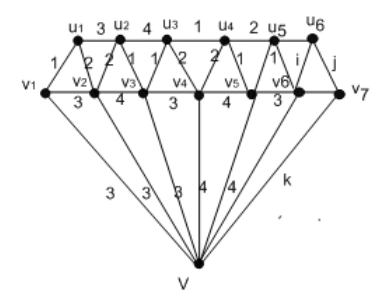

Gambar 4. Graf $\operatorname{src}\left(B r_{7}\right)=t-1$ dengan $i \in[1, t-1], j \in[1, t-1], k \in[1, t-1]$

Tanpa mengurangi perumuman, perhatikan Gambar 4. Misalkan $c^{*}$ adalah suatu strong rainbow $t-1$ geodesic. Dengan memberi warna $c^{*}\left(v v_{7}\right)=1, c^{*}\left(v_{7} u_{6}\right)=3$, dan $c^{*}\left(v_{6} u_{6}\right)=4$ maka tidak ada rainbow $u_{1}-u_{6}$ geodesic. Jika $c^{*}\left(v v_{7}\right)=2$, $c^{*}\left(v_{7} u_{6}\right)=4, c^{*}\left(v_{6} u_{6}\right)=3$ maka tidak ada rainbow $u_{1}-u_{6}$ geodesic. Jika $\left(v v_{7}\right)=3$ maka tidak ada rainbow $v_{1}-v_{7}$ geodesic. Jika $c^{*}\left(v v_{7}\right)=4$ maka tidak ada rainbow 
$c^{*}\left(v_{4}-v_{7}\right)$ geodesic. Ini membuktikan bahwa $\operatorname{src}\left(B r_{7}\right) \neq t-1$ sehingga haruslah $\operatorname{src}\left(B r_{7}\right) \geq t$. Dengan demikian dapat dibuktikan $\operatorname{src}\left(B r_{n}\right) \geq t$ untuk $n \geq 7$.

Selanjutnya akan ditunjukkan bahwa $\operatorname{src}\left(B r_{n}\right) \leq t$. Definisikan pewarnaan $c$ : $E(G) \rightarrow\{1,2, \cdots, t\}$ sebagai berikut :

$$
\begin{aligned}
c\left(v v_{i}\right) & =\left\lceil\frac{i}{3}\right\rceil+2, \text { untuk } i \in\{1,2, \cdots, n\} ; \\
c\left(u_{i} u_{i+1}\right) & =((i+1) \bmod 4)+1, \text { untuk } i \in\{1,2, \cdots, n-1\}, \\
c\left(v_{i} v_{i+1}\right) & =((i+1) \bmod 2)+3, \text { untuk } i \in\{1,2, \cdots, n-1\}, \\
c\left(u_{i} v_{i}\right) & =((i+1) \bmod 2)+1, \text { untuk } i \in\{1,2, \cdots, n-1\}, \\
c\left(u_{i} v_{i+1}\right) & =i \bmod 2+1, \text { untuk } i \in\{1,2, \cdots, n-1\} .
\end{aligned}
$$

Selanjutnya, ditunjukkan bahwa untuk setiap $x$ dan $y$ di $V\left(B r_{n}\right)$ dengan $d(x, y) \geq 2$, terdapat path $x-y$ yang merupakan strong rainbow path.

Sub-kasus 2.1 Jika $x=v$ dan $y=u_{i}$, maka terdapat geodesic path $v, v_{i}, u_{i}$. Contoh : $v, v_{1}, u_{1}$.

Sub-kasus 2.2 Misalkan $x=u_{i}$ dan $y=u_{j}$.

Jika $j-i=2$, maka terdapat geodesic path $u_{i}, u_{i+1}, u_{j}$.

Contoh : $u_{1}, u_{2}, u_{3}$.

Jika $j-i=3$, maka terdapat geodesic path $u_{i}, u_{i+1}, u_{i+2}, u_{j}$.

Contoh : $u_{1}, u_{2}, u_{3}, u_{4}$.

Jika $j-i \geq 4$, maka terdapat geodesic path $u_{i}, v_{i}, v, v_{j}, u_{j}$.

Contoh : $u_{1}, v_{1}, v, v_{5}, u_{5}$.

Sub-kasus 2.3 Misalkan $x=v_{i}$, dan $y=v_{j}$, dan $i<j$.

Jika $j-i=2$, maka terdapat geodesic path $v_{i}, v_{i+1}, v_{j}$.

Contoh : $v_{1}, v_{2}, v_{3}$

Jika $j-i \geq 2$, maka terdapat geodesic path $v_{j}, v_{j-1}, v_{i}$.

Contoh : $v_{4}, v_{3}, v_{1}$.

Sub-kasus 2.4 Misalkan $x=v_{i}$ dan $y=u_{j}$.

Jika $j-i=2$, maka terdapat geodesic path $v_{i}, v_{i+1}, v_{j}, u_{j}$.

Contoh : $v_{2}, v_{3}, v_{4}, u_{4}$.

Jika $i-j=2$, maka terdapat geodesic path $v_{i}, v_{i-1}, u_{i}$.

Contoh : $v_{4}, v_{3}, u_{2}$.

Jika $|j-i|>3$, maka terdapat geodesic path $v_{i}, v, v_{j+1}, u_{j}$.

Contoh : $v_{5}, v, v_{2}, u_{1}$.

Jadi, pewarnaan di atas merupakan suatu pewarnaan strong rainbow. Karena itu, $\operatorname{src}\left(B r_{n}\right)=t$ untuk $n \geq 6$.

Sebagai contoh pada Gambar 5 dibuat suatu pewarnaan-5 strong rainbow pada $\mathrm{Br}_{9}$.

\section{Ucapan Terima Kasih}

Penulis mengucapkan terima kasih kepada Bapak Prof. Dr. Syafrizal Sy, Bapak Narwen, M.Si, Ibu Dr. Lyra Yulianti, Bapak Drs. Syafruddin, M.Si, Bapak Bukti Ginting, M.Si yang telah memberikan masukan dan saran sehingga makalah ini dapat diselesaikan dengan baik. 
$r c\left(B r_{n}\right)$ dan $\operatorname{src}\left(B r_{n}\right) \quad 99$

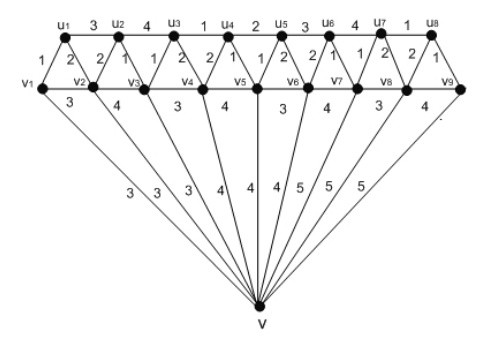

Gambar 5. Pewarnaan-5 pada $B r_{9}$

\section{Daftar Pustaka}

[1] Chartrand, G. dkk. 2008. Rainbow Connection in Graphs, Math. Bohem. 133: $85-98$

[2] Diestel, R. (2010). Graph Theory, Springer.

[3] Krivelevich, M. dan Yuster, R. 2010. The rainbow connection of a graph is (at most) reciprocal to its minimum degree, School of Mathematics, Tel Aviv University.

[4] M. A Shulhany dan A. N. M Salman. 2015. Bilangan terhubung pelangi graf berlian. Prosiding Seminar Nasinonal Matematika dan Pendidikan Matematika $U M S$.

[5] O. Schnetz. Evaluation of period of a family of triangle and box ladder graphs. ArXiv : 1210.5376. 